\title{
TECHNICAL NOTE \\ EXPLORING TRADITIONAL GLASS BEAD MAKING TECHNIQUES IN JEWELLERY
}

\author{
I. K. Agyei', J. Adu-Agyem ${ }^{2}$ and R. Steiner ${ }^{3}$ \\ ${ }^{1}$ Department of of Industrial Art, KNUST, Kumasi, Ghana \\ ${ }^{2}$ Department of General Art Studies, KNUST, Kumasi, Ghana \\ ${ }^{3}$ Department of Integrated Rural Art and Industry, KNUST, Kumasi, Ghana
}

\begin{abstract}
Exploring traditional glass bead making techniques in jewellery in some prominent areas in Ghana is a means to exposing the area for metal and ceramic artists and other related fields of discipline such as aesthetics and criticism to complement their form of art for a better livelihood and diversification in jewellery. There are several methods for producing glass beads in other countries. Emphasis is placed on traditional technique in some areas in Ghana as well as the processes involved which are mostly identified by the indigenous or traditional glass bead makers. Materials for glass bead making are very cheap and readily available as compared to other materials for bead making such as metal, stone and others. One needs not become an artist before engaging in glass bead making, because the techniques or skills involved are not complex and can be learnt easily. Glass bead making techniques and their mass production will help the individual and the nation to earn foreign exchange from the export market. This publication, therefore, seeks to demonstrate and expose the traditional techniques of glass bead making to artists in Ghana and other parts of the world. It is also a means to solving the problem of export diversification from traditional exports such as gold, timber and cocoa to compete with other products on the world market. This will as well complement other forms of local jewellery for export in Ghana. Experimental and Descriptive research methods were used. Critical observation of the materials, tools, equipment and the technique were paramount in this research. Interviews were also conducted to authenticate the facts gathered. It is recommended that artists, institutions and the small scale industries attach much importance to the production of glass beads for livelihood and export by improving on the techniques of production.
\end{abstract}

Keywords: livelihood, vitreous, glass bottles, furnace, threading

\section{INTRODUCTION}

Dierks (1994) believes that jewellery making is a craft practically as old as humanity itself and ever since our ancestors made their homes in caves, people have created and worn body or- naments. Jewellery has been made to bring good fortune, to indicate social standing or merely to express one's personality.

Holland (1999) also opines that jewellery is a 


\section{Agyei et al.}

personal ornament such as necklaces, rings or bracelets made from jewels, precious metals or other substances. To him, the term jewellery is derived from the word 'jewel' which was anglicised from the Old French word juel' (meaning 'play thing', an enjoyable object, etc.) around the $13^{\text {th }}$ Century. Out of jewellery emerged other forms like the glass beads.

Dusbin (1987) echoes that the type of material depends largely on the availability of raw materials and the technology of the people. According to him, bead making has been largely influenced by environmental factors.

Fitch (1992) traces the history of glass bead making from Western Asia and dates back to the third millennium BC. Glass beads are still produced in every corner of the world. Both Africans and Native Americans integrate European beads with their own tradition of colour and jewellery design.

In Africa and for that matter Ghana, beads are merely part of an assemblage or a mixture of materials such as twigs, seeds, shells, metals, bones, ceramic wares and glass put on as necklace or article of jewellery in a seemingly haphazard way so that the object may not appear to have been designed (Avotri, 2009; KankamDwumfour, 2011). Ancient glass is a compound of silica, lime and soda in the following proportions: Silica has $57-72 \%$, Lime has $3-10 \%$ and Soda has $9-21 \%$.

Glass beads often serve as a mirror of the culture and speak a lot about the social, political, religious and economic history and status of those who made and used them.

Among some ethnic groups e.g. the Krobos of Ghana, glass beads are worn from birth to death and are buried together with their owners. The beauty of glass beads increases with use and time.

In Ghana glass beads also form part of the communication system of the multiple layers of the
Ghanaian society. Decorations with glass beads communicate cultural values in a symbolic language which expresses status, religion, politics and artistic attitudes (Asumadu, Personal Communication, 2010).

In societies without the written word, art objects acquire vital importance as visual documents, and serve to transmit traditional knowledge. They constitute a dense concentration of ancestral wisdom that has to be preserved and passed on to the next generations and, being another form of jewellery, play significant role (Adu-Agyem, 2007; Agyei, 2009).

\section{MATERIALS AND METHODS}

\section{Materials}

In Ghana, some of the materials used for making glass beads are pieces of glass, firewood for fuelling the kilns, metal mortar, pestle, grinding stone, bodkin, bead holder, bricks and cassava leaf stalk.

Materials and other resources required are mainly bottles of a specific make that is compatible to the other composite materials like ceramic and other powdered pigments when they are subjected to high temperatures (See Fig. 1). The bottles are purchased by agents who roam from house to house looking for these bottles to buy and some are also purchased from Europe since not all the coloured bottles are available locally. Among the local resources are the ceramic or powdered pigment and fire-wood to fuel the kiln. The kiln is usually constructed from local materials (See Fig. 2).

\section{Methodology}

Preparation of the materials is not elaborate. The bottles are washed and sorted out for their compatibility. Next, they are broken into pieces with a metallic pestle and crushed into powder in a metallic mortar. The powder is sieved and the smooth grains, which may pass through 300 grades, are collected and pigment is added to it. The colour design is determined at this stage, followed by firing. The hot, molten liquid glass 


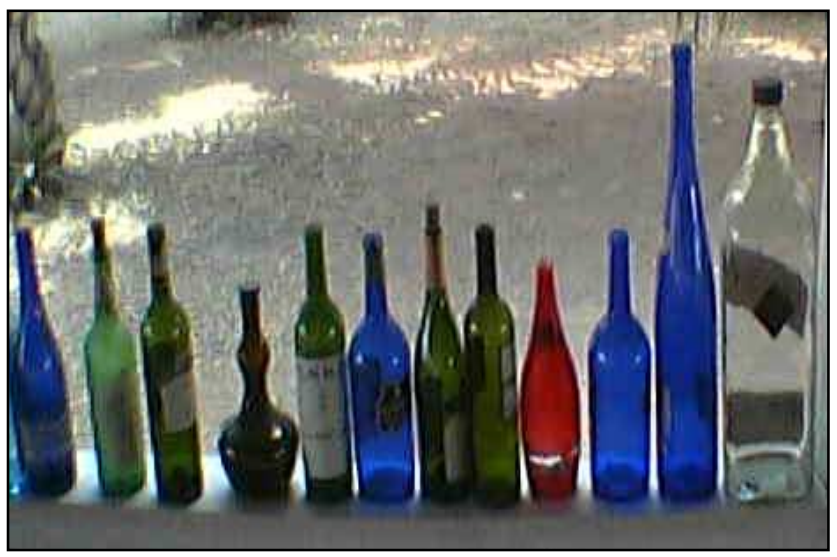

Fig.1: Bottles for making glass beads

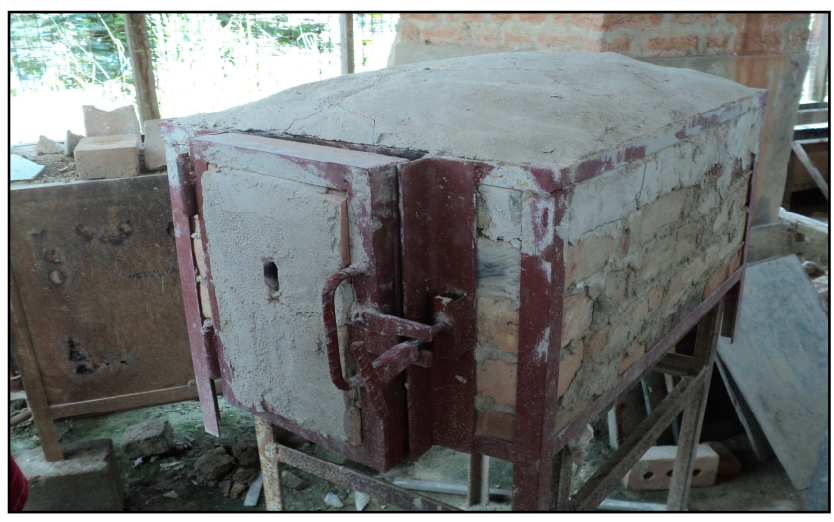

Fig. 2: Kiln for firing beads

is poured into moulds. In the case of one type of mould, a metal rod runs through its centre. In another type, the mould contains several bowlshaped forms. A piece of the leaf stalk of cassava was fixed to the centre of the bowl-shaped depression. It is then left to cool down. After it is fired, it is collected into a specially built tumbler, washed and dried. It is then annealed and preserved.

The Descriptive method was used to describe the tools and materials used for glass bead making, types of glass beads and the techniques for making these glass beads. This was expedient for the design and making of the glass beads. Procedures from designing to finishing of the beads were described and analysed.

The Experimental research method was employed to assess the suitability of the requisite tools and materials for the making of the glass beads for jewellery. Experiments were conducted to find out the suitability of the techniques of preparing the glass and finishing it for bead making. The population for the study involved eleven glass bead makers at Krobo in the Eastern Region and Daabaa near Akropong in the Atwima Nwabiagya District in Ashanti Region respectively. Since it is practically impossible to reach all the people who manufacture glass beads in these two regions, only two people including their family members from 
Cedi Beads Industry in Odumasi Krobo and Daabaa in the Atwima Nwabiagya District in Ashanti were chosen. These two people from these areas were chosen because they were more knowledgeable, productive, popular and friendly. The purposive sampling method was employed to select these two areas. This method of sampling made it possible to select these two areas with similar characteristics from the accessible areas which give a true reflection of traditional glass bead making in Ghana.

Observation which, to Leedy and Ormrod (2005), Best and Kahn (1998) believe is to triangulate data obtained was used to ascertain information given by four glass bead makers who were interviewed.

\section{RESULTS AND DISCUSSION}

This section provides a discussion and analysis of the results of the step-by-step procedure and technique, suitability of the materials, tools and equipment for the production of the finished glass beads for jewellery.

\section{Design Processes}

Making design patterns for glass beads is very important because the outcome of a complete bead basically depends on it. Before one starts making a piece of glass bead for jewellery, one must decide how long it should be, how many beads he or she requires and more importantly, the type of pattern it will have. In some necklaces the beads are graduated in size. Some necklaces have a repeated pattern and others are strung randomly. In planning and determining the length of a necklace, it was always better to arrange the designs by laying out all the glass beads before starting to thread them together. Threading started from the centre before the sides.

A clasp was attached after being satisfied with the result. A necklace usually measures $50 \mathrm{~cm}-$ $60 \mathrm{~cm}$ while a bracelet is about $25 \mathrm{~cm}$ long, depending on the size of one's wrist.
The basis of creating glass bead necklaces, the art of producing patterns sometimes often confuse the novice in jewellery production. Prior to pattern making was the need to choose a length. One of the excitements in making glass bead jewellery is taking into consideration the length of the necklace with its height, the clothes to match and the occasion on which the beads will be worn. Using a selected measurement as a guide, $10 \mathrm{~cm}$ extra thread for making knots and clasps were attached.

There was also the need to calculate the number of glass beads needed. Beads are traditionally measured in millimetres. To work out how many glass beads were needed, the length of the sequence intended to use was measured and the number divided into the length of the necklace. A good choker length usually is about $40 \mathrm{~cm}$. There are various ways of making patterns in glass bead jewellery, such as a necklace. An unevenly recurring sequence is an interesting alternative to the usual repeating pattern. Pattern working will ultimately determine what the outcome of glass bead jewellery will be after a complete process.

\section{Working Processes or Techniques}

To prepare the mould for casting glass beads, clay was collected from a clay pit at a river side. The clay was allowed to dry completely. It then became easier to remove large particles of unwanted matter such as roots, leaves, wood and pebbles.

The next process was to pound the clay into fine powder and to sieve the pounded clay to get rid of small bits of unwanted materials, using a wire mesh. A little water was added to the powdered clay such that it could be manipulated more easily. A lump of clay was formed and kneaded to remove the air bubbles trapped in it. Occasionally, the clay lump was cut through with a cutting wire or a sharp knife and inspected to make sure that all air bubbles were removed. The pieces were slammed together and kneaded again. 
After preparing the clay, a slab of standard thickness was moulded taking into consideration the size of the beads to be produced. A rectangular or circular object was placed on the slab and traced to get the outline. A sharp knife was used to cut the drawn shape or outline from the clay slab. The cut shape was allowed to dry up to the leatherhard stage. While the shaped clay pieces were setting, a piece of wood was shaped leaving a small projection at the tip (Fig. 3).

"Foa" which is a piece of shaped wood (fig. 3) was used to make cavities in the clay mould into which powdered glass would later be poured. When the clay slab was leatherhard, the shaped tool was carefully placed on it uprightly at an angle of 90 degrees to the slab. The tool was pushed into the slab carefully to create a pit. The projection at the tip of the tool created

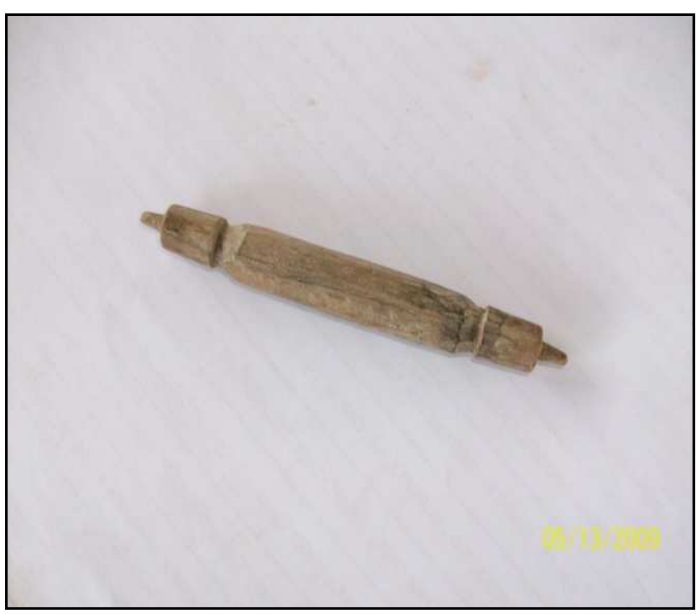

Fig. 3: Piece of wood locally called "Foa" an extended pit. Cassava stalk would be stuck into this extension later to create the threading hole in the glass bead (Fig. 4). This pit-making exercise was repeated to create about 39 pits, per slab, depending on the size of bead to be produced (See Fig. 5). Several other moulds were made by this method and left to dry.

\section{Preparation of Glass Powder}

Fine glass powder is the main ingredient or ma- terial for the making of glass beads. To obtain glass powder, broken bottles or louvre blades (Fig. 6) were collected from the community.

Broken bottles were grouped into various colours of powder for designing the beads. After this, each colour was put separately in a metal mortar and pounded with a metal pestle into fine powder. (Fig. 7). The pounded glass was

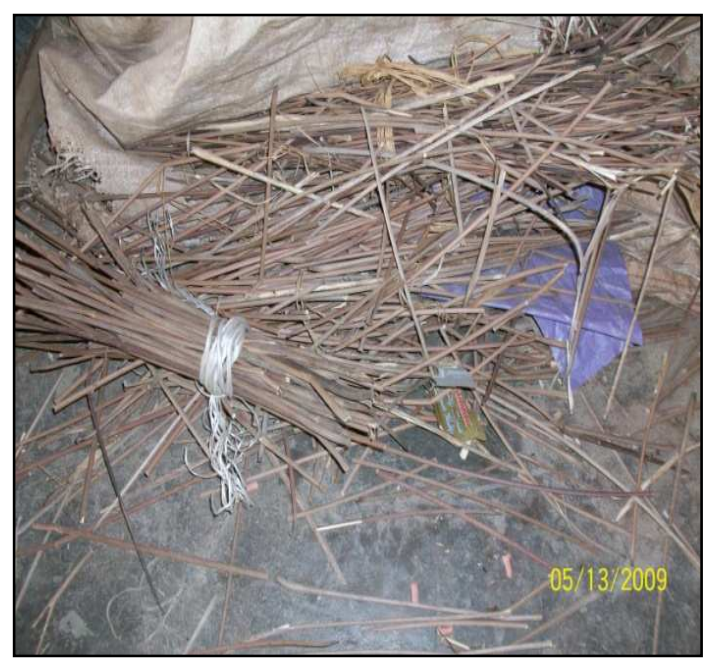

Fig. 4: Pieces of cassava stalks for creating holes in beads

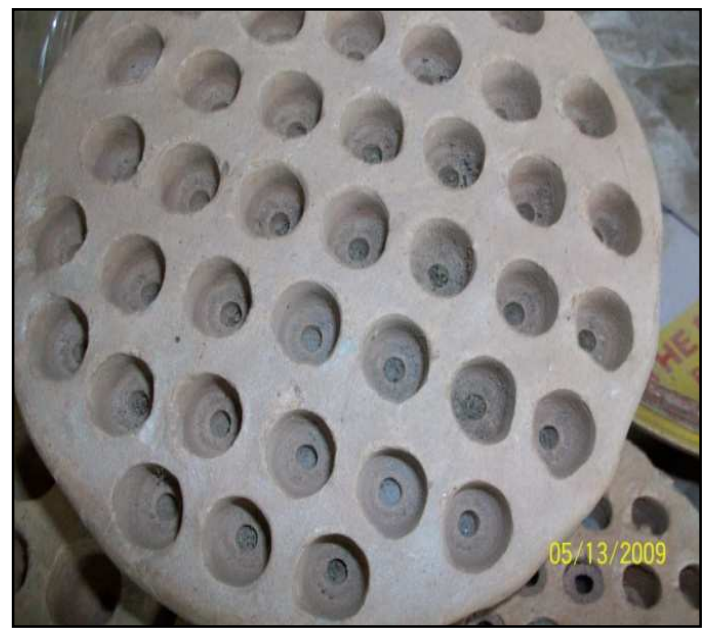

Fig. 5: Mould for bead casting

(Note the small, extended pits at the base of the larger pits) 
108

\section{Agyei et al.}

sieved to get the finest for casting. As a safety measure, the nose and mouth were covered during pounding to prevent inhaling the glass dust. Goggles are put on to protect the eyes.

Various grades of mesh were used to sieve the glass powder starting from course to fine grade and then the glass powder was put into a plastic container and covered very well (Fig. 8).

At this stage, cassava leaf stalks were obtained and allowed to dry. Clay solution with a light consistency was prepared. The moulds were then immersed into the clay solution and allowed to dry. The activity was repeated to make sure that all pores in the mould were sealed off. When the moulds were dry, the cassava leaf stalks were cut into pieces of the same size. The stalks were put into each of the lower pits in the larger pits in the mould. Care was taken to secure the stalks in the small pits (Fig. 9).

The moulds were filled with the glass powder with a simple manual technique and the use of a small container. Also layers of coloured glass powder were filled into the holes to create patterns. A pin was used to pinch the side of the

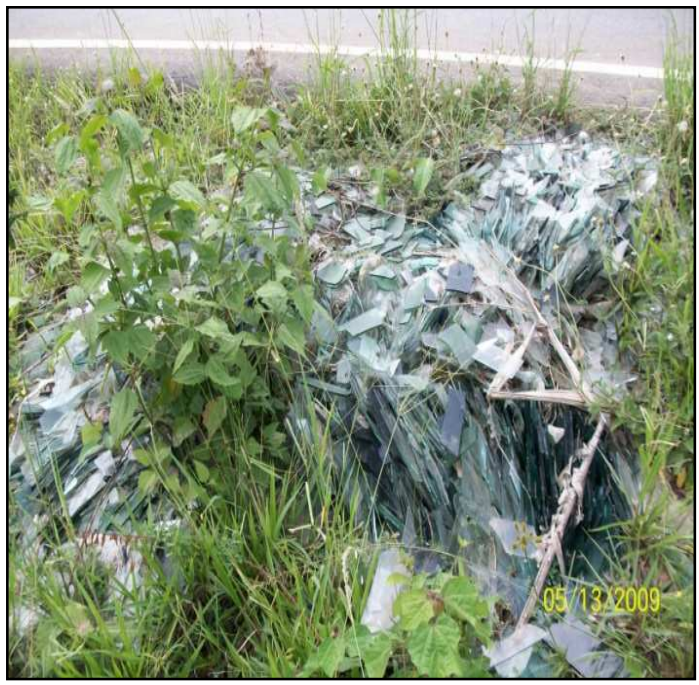

Fig. 6: Broken pieces of glass and bottles holes to allow various layers of colour to flow into each other (See Fig. 10).

The mould was well shaken to make sure that the cavities were firmly filled. More powder was added to top the fillings where necessary.

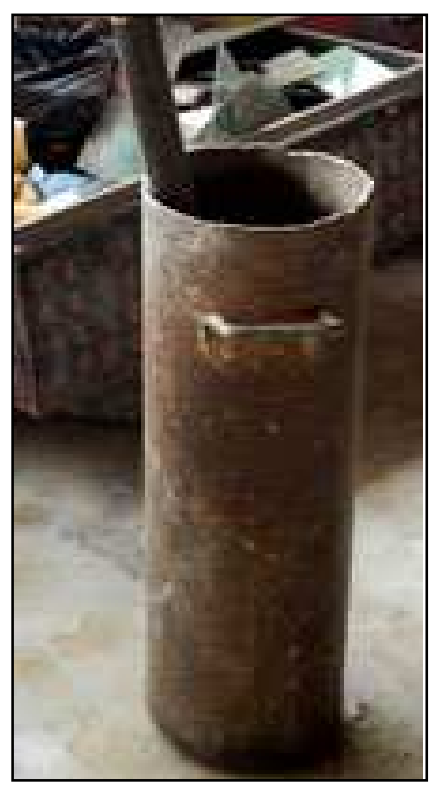

Fig. 7: Metal mortar and pestle

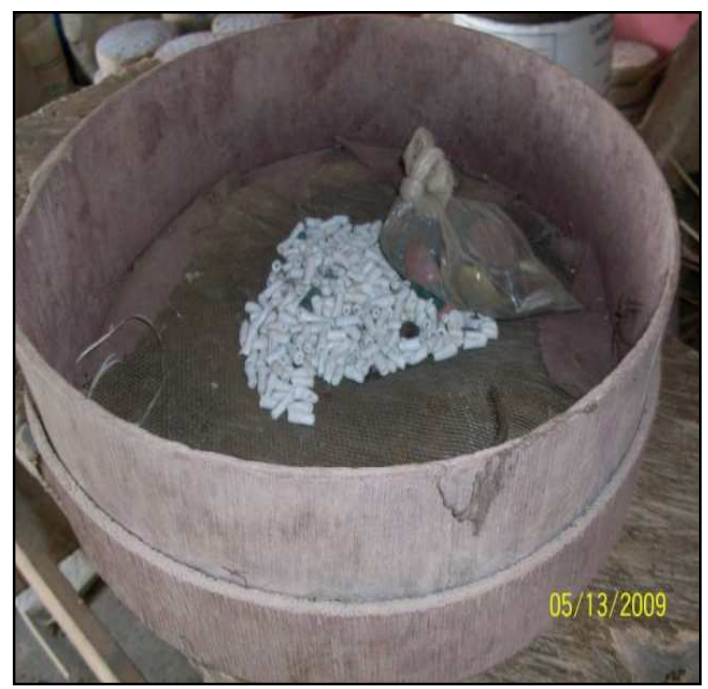

Fig. 8: Sieve for sieving the pounded glass

Journal of Science and Technology @ C KNUST December 2012 
Traditional glass bead making... 109

The surfaces of the moulds were cleaned of excess glass powder (Fig. 11). The moulds were prevented from getting into contact with water since the moisture would cause cracking during firing and interfere with the design.

The filled moulds were packed carefully in the kiln in the brick-laying formation to avoid breakage (Fig. 12).

Most normal glasses melt at a temperature of $900^{\circ} \mathrm{c}$. The spy hole in the kiln was used to peep into through the kiln to find out whether the glass had melted. To avoid scalding or searing, looking into the kiln was done from a distance of about one metre.

When the melting of the glass matured, the fire was quenched and the kiln allowed to cool down slowly for nearly 48 hours. The traditional beadmakers explained that if cold air was allowed to rush through, newly solidified beads would suffer temperature shock, and this would cause them to crack and develop warps, crimples and creases in the remaining beads. The moulds were removed from the kiln with the

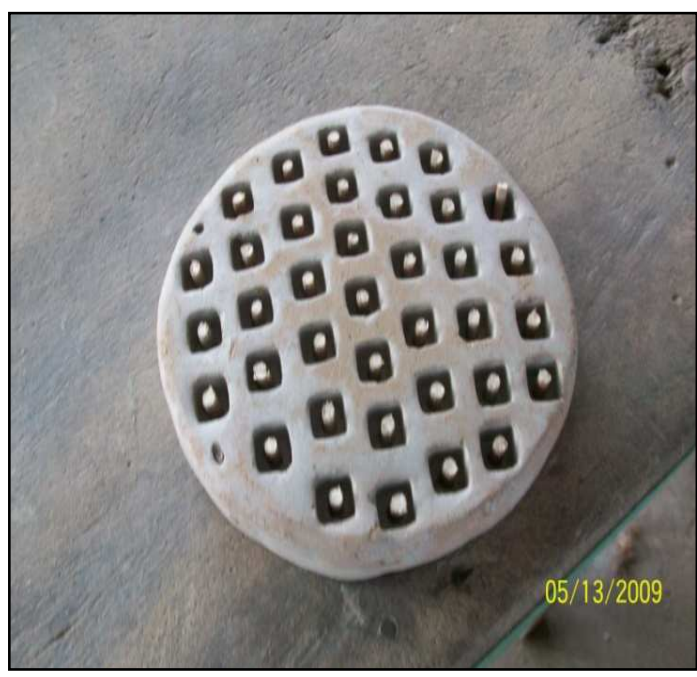

Fig. 9: Mould with cassava leaf stalks stuck into them

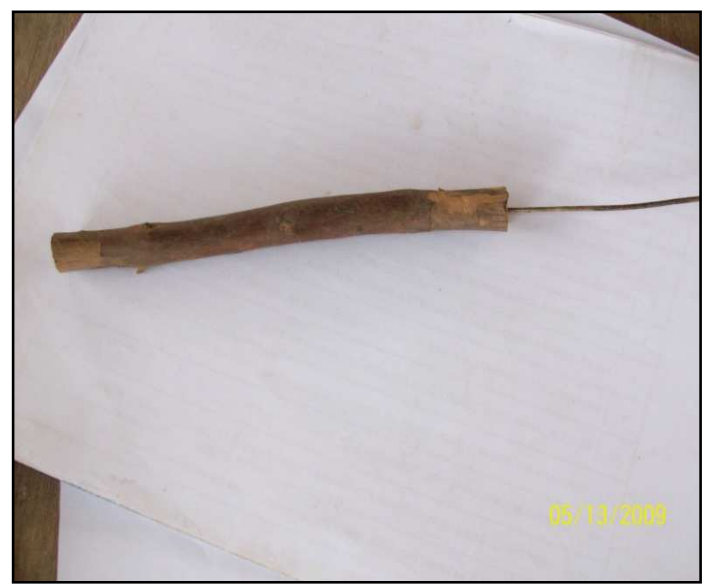

Fig. 10: Pin with a wooden handle

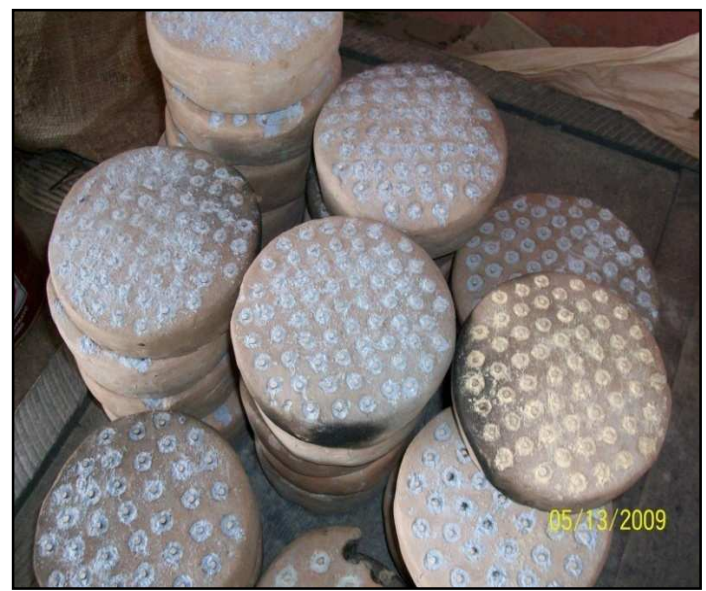

Fig. 11: Moulds filled ready for firing

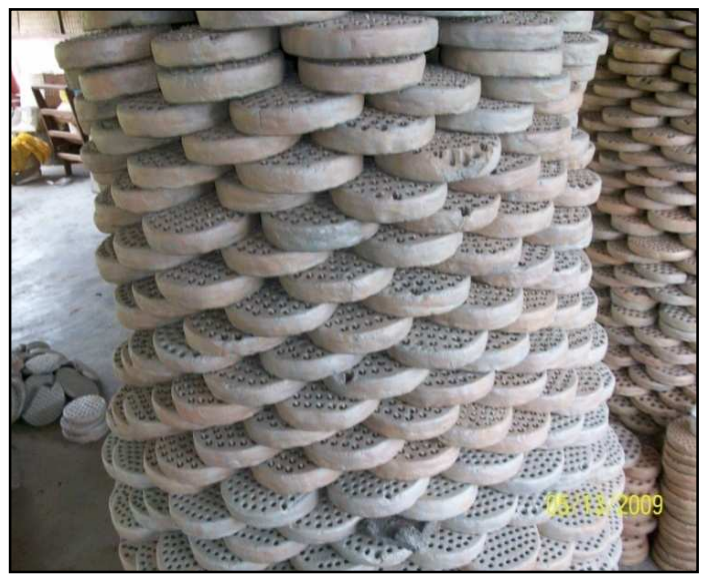

Fig. 12 : Packed moulds 


\section{Agyei et al.}

small spade with a long handle and allowed to cool down and set completely. The cast beads were removed gradually and put in a water container for washing (See Figs. 14 and 15).

The cast beads are then ready to undergo finishing using the processes such as smoothing, sanding and polishing.

Smoothing beads by sanding, grinding and polishing

Surface of most of the new beads were rough and needed to be smoothened and cleaned. To

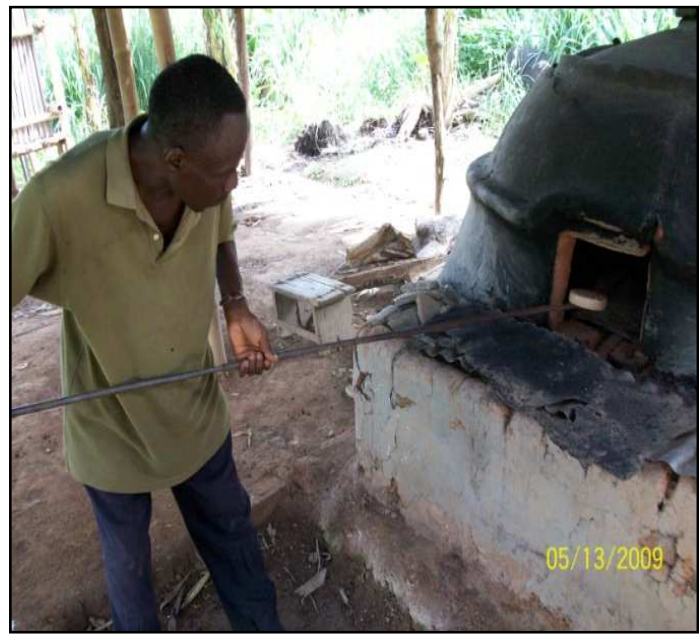

Fig. 13: Packaging mould into kiln Courtesy of Mr. Asumadu, beadmaker at Daabaa

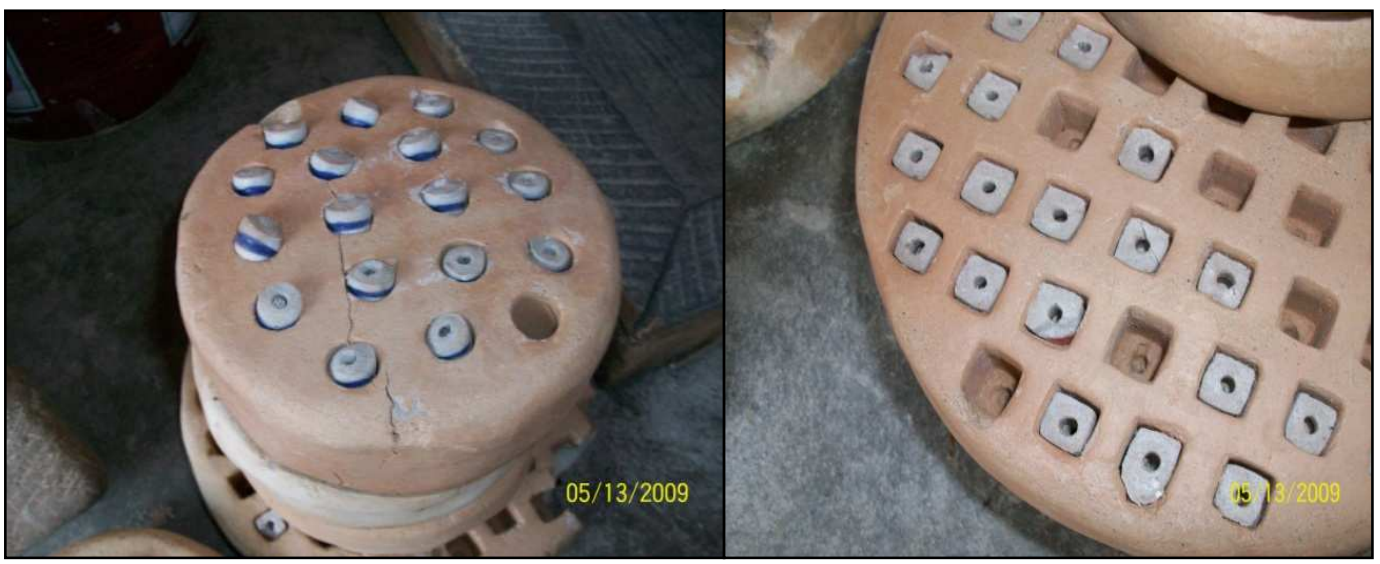

Fig.14: The newly cast beads in their moulds

Journal of Science and Technology ㄱ KNUST December 2012 smoothen the beads, the following steps were considered:

The beads were placed on a flat surface of a stone and metal wire was used to thread them together. The beads were rubbed against the stone carefully to smoothen them. (See Fig. 16). To smooth them further, a stick was put or fixed through them and held against the revolving stone of a grinding machine.

Care was taken to prevent injury. Fine sandpaper was another alternative used to smoothen

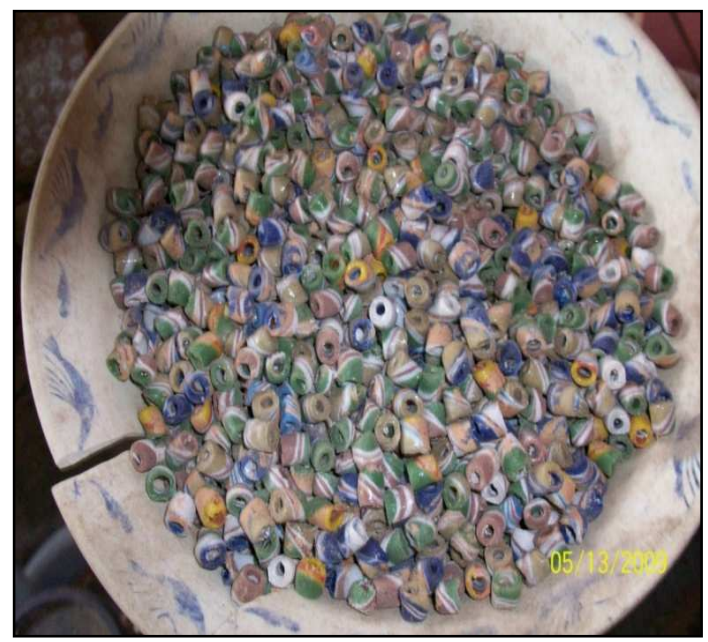

Fig. 15: Cast beads removed from mould 
Traditional glass bead making... 111

the beads.

With the help of a needle and thread, the beads were put together to form necklaces, bangles and pendants. Other items such as earrings were also made from the beads (Fig.17).

\section{CONCLUSION}

The study explored the traditional methods of glass bead making for jewellery such as ear rings, bracelets and necklaces. Exploring and exposing the techniques would go a long way to help readers, metal artists and other researchers delve deeper into it for mass production and export to help boost the economy and culture of Ghana.

The research also shows that broken bottles which otherwise pose an environmental hazard due to poor disposal methods, is recycled for economic advantage. The glass bead industry is regardless of its many challenges, a promising tourism potential to be developed further to create employment and to enhance its contribu-

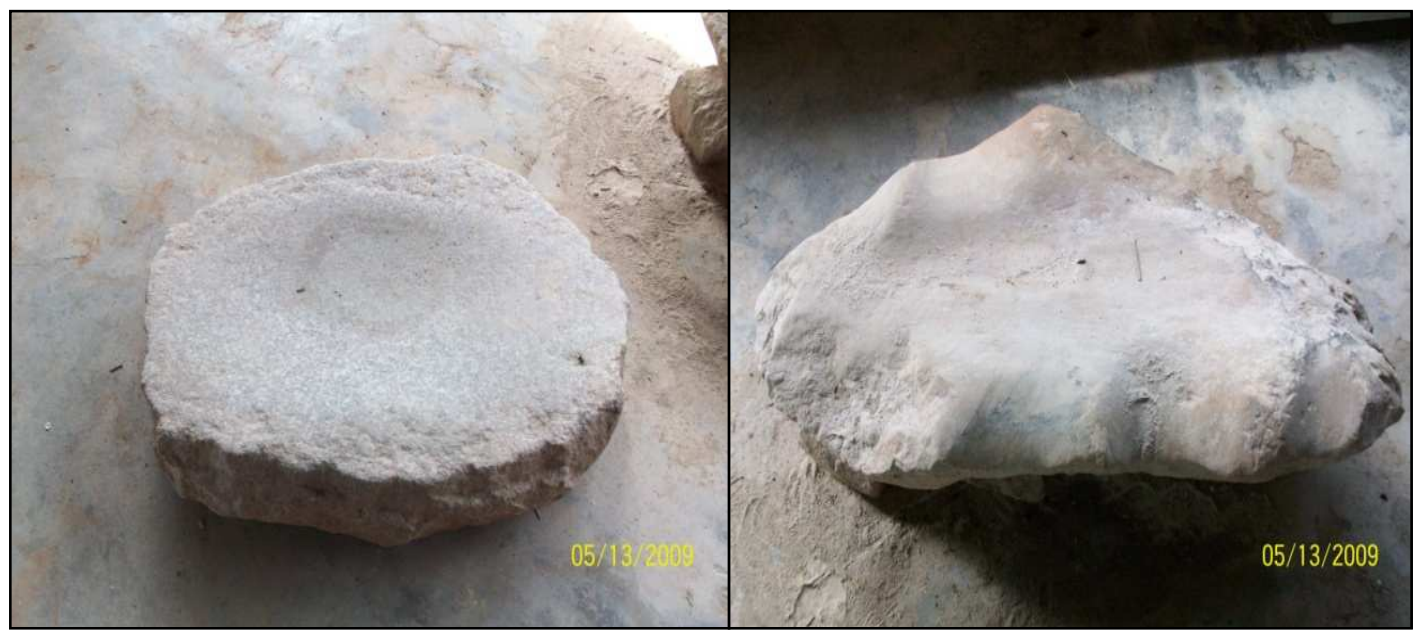

Fig. 16: Grinding stones for smoothing the beads

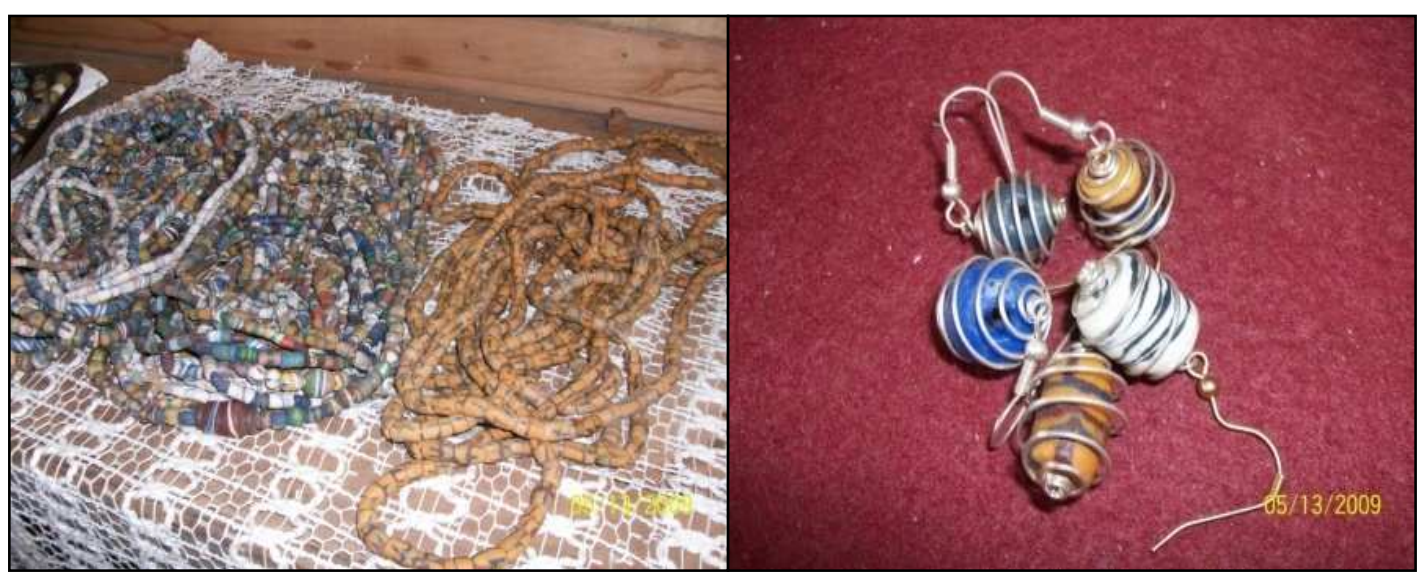

Fig. 17: Finished beads, necklaces, bracelets and earrings

Journal of Science and Technology ㄱ KNUST December 2012 


\section{Agyei et al.}

tion to the Gross Domestic Product of Ghana. Even the developed countries such as Great Britain, the United States of America and the Netherlands, who are far advanced in technology, have bead markets and museums that attract visitors to learn the history and culture, not only of indigenous bead making techniques, but also of the people who made those beads.

The techniques are user friendly and could be practised by all to create employment for the youth. Non governmental organizations (NGOs) and other government establishments that offer assistance to small and medium scale industries should re-strategise to make their services more accessible towards the recycling of, as well as reorganise the glass beads producers into a more vibrant industry.

Thus, an effort to rejuvenate this sector will go a long way to help revitalize Ghana's economy and culture.

\section{REFERENCES}

Adu-Agyem, J. (2007). Beads Speak: The Aesthetics of Daabaa Beads. Unpublished manuscript, Department of General Art Studies, KNUST.

Agyei, I. K. (2009). Jewellery for Senior High Schools, Kumasi. unpublished manuscript, Department of Industrial Art, KNUST.

Avotri, N. V. K. (2009). The bead Culture amo- ong the Krobo's of Ghana, PhD Thesis. KNUST, Kumasi; Department of General Art Studies Library.

Best, J. W. and Kahn, J. V. (1998). Research in Education, Culture of Reading ( $8^{\text {th }}$ Edition). USA: A Viacom Company.

Dierks, L. (1994). Creative Clay Jewelry, extraordinary, colourful, fun designs to make from polymer day. USA: Altamout Press.

Dusbin, L. S. (1987). The history of Beads from 30,000 BC to the present. London: Harry N. Abeams Incorporated.

Fitch, J. (1992). The art and craft of jewellery a practical guide to high-style, low-cost design. Canada: General Publishing Company Limited.

Holland, J. (1999). The King Fisher Encyclopaedia. London: King Fisher Books.

Kankam-Dwumfour, E. (2011). Recycled glass bead production in selected towns in Ashanti. M.Phil Thesis, KNUST, Kumasi: Department of General Art Studies.

Leedy, P. D. and Ormrod, J. E. (2005). Practical Research; Planning and Design, $\left(8^{\text {th }}\right.$ Edition). Upper Saddle River, New Jersey: Pearson Education, Inc. 